\title{
The Influence of Hypertonic Mannitol on
}

\section{Regional Myocardial Blood Flow during}

\author{
Acute and Chronic Myocardial Ischemia
}

\author{
in Anesthetized and Awake Intact Dogs
}

\author{
James T. Willerson, John T. Watson, Ian Hutton, David E. Fixier, \\ George C. Curry, and Gordon H. Templeton \\ From the Pauline and Adolph Weinberger Laboratory for Cardiopulmonary \\ Research of the Department of Internal Medicine, and the Departments \\ of Surgery, Pediatrics, and Radiology, University of Texas Southwestern \\ Medical School at Dallas, Dallas, Texas 75235
}

A B S T RACT The influence of hypertonic mannitol on regional myocardial blood flow and ventricular performance was studied during acute myocardial ischemia in awake, unsedated and in anesthesized dogs and after myocardial infarction in awake unsedated dogs. Regional myocardial blood flow was measured with radioactive microspheres. Generalized increases in regional myocardial blood flow occurred after mannitol in all of the different animal models studied. The increases in coronary blood flow after mannitol were just as impressive in the nonischemic regions as in the ischemic portion of the left ventricle in all of the different models that were examined in this study.

Improvement in regional myocardial blood flow to the ischemic area of the left ventricle after mannitol was associated with a reduction in ST segment elevation during acute myocardial ischemia in anesthetized dogs. The increases in regional myocardial flow after mannitol were also associated with increases in contractility, but the increases in flow appeared to be more impressive than the changes in contractility. The data obtained demonstrate that mannitol increases regional coronary blood flow to both ischemic and nonischemic myocardium in both anesthetized and awake, unsedated, intact dogs with acute and chronic myocardial ischemia and that mannitol reduces ST segment elevation dur-

Dr. Hutton was supported by a British-American Research Fellowship from the American Heart Association, Inc., during the time this work was performed. His present address is: University Department of Medical Cardiology, the Royal Infirmary, Glasgow, Scotland. Dr. Willerson is an Established Investigator of the American Heart Association.

Received for publication 30 November 1973 and in revised form 30 December 1974. ing acute myocardial ischemia in anesthetized dogs. Thus the results suggest that under these circumstances the increases in regional myocardial blood flow after mannitol are of physiological importance in reducing the extent of myocardial injury. Since coronary blood flow increased to nonischemic regions the increases in regional myocardial flow demonstrated in this study after mannitol cannot be entirely explained by the mechanism of reduction in ischemic cell swelling.

\section{INTRODUCTION}

Pretreatment with hypertonic mannitol has been shown to improve ventricular function and increase total coronary blood flow during acute myocardial ischemia in anesthetized dogs and to increase collateral coronary blood flow and reduce the area of myocardial damage in isolated perfused canine hearts (1). The present study was performed to determine whether hypertonic mannitol produces: (a) the same beneficial effect in regional myocardial blood flow in the intact dog whether it is given before or after the onset of coronary occlusion, (b) the same increase in regional myocardial blood flow in both anesthetized and awake, unsedated dogs with either acute or chronic myocardial ischemia, (c) increases in myocardial blood flow only in ischemic areas or throughout ischemic and nonischemic regions, and $(d)$ the same changes in regional myocardial blood flow and ventricular performance regardless of the rate of administration.

\section{METHODS}

\section{Anesthetized studies}

These experiments were done on right heart bypass. Adult dogs of either sex weighing between 15 and $35 \mathrm{~kg}$ were 
anesthetized with intravenous chloralose $(60 \mathrm{mg} / \mathrm{kg})$. An endotracheal tube was inserted and ventilation provided by a Harvard respirator (Harvard Apparatus Co., Inc., Millis, Mass.) using $95 \%$ oxygen and $5 \%$ carbon dioxide. The chest was opened through a median sternotomy, the superior and inferior venae cavae cannulated, and the azygous vein divided. The caval return was directed to a reservoir through a bubble oxygenator and heat exchanger $\left(37 \pm 0.5^{\circ} \mathrm{C}\right)$ and then returned through a variable-speed calibrated roller pump to the main pulmonary artery. The rate of pumping into the pulmonary artery therefore controlled cardiac output. It was possible to switch from right heart bypass to total cardiopulmonary bypass by inserting a catheter in the left subclavian artery and using this as an alternate source of perfusion whenever desired. A ligature was placed around the main pulmonary artery thus isolating the right heart, which received only coronary venous drainage. Left ventricular pressure and the maximal rate of left ventricular pressure rise $(\mathrm{LV} \mathrm{d} p / \mathrm{d} t)^{1}$ were measured by using a Millar pressure transducer catheter (PC-480) and TCB 107 amplifier (frequency response $0-20 \mathrm{kHz}$ ). Proximal aortic pressure was also measured through a short, wide-bore polyethylene catheter inserted into the aortic arch through the left carotid artery. Heart rate was kept constant by atrial pacing after sinoatrial node crush. Left ventricular and systemic arterial pressures were recorded with Statham P231a pressure transducers (Statham Instruments, Inc., Oxnard, Calif.) and recorded on multichannel Siemens (Iselin, N. J.), Hewlett-Packard (Palo Alto, Calif.), or Electronics for Medicine (White Plains, N. Y.) direct writing recorders. Arterial blood gases, hematocrits, and osmolalities (freezing point determination method; range of error $\pm 3 \mathrm{mosmol} / \mathrm{kg}$ ) were determined during each intervention.

Regional myocardial blood flow was measured with radioactive microspheres $9 \mu \mathrm{m}$ in diameter $\left({ }^{141} \mathrm{Ce},{ }^{85} \mathrm{Sr}\right.$, and ${ }^{\left.{ }^{\circ} \mathrm{Sc}\right)}$ (3M Co., St. Paul, Minn.). Microspheres $15 \mu \mathrm{m}$ in diameter $\left.{ }^{125} \mathrm{I}\right)$ were used for control flow determinations in experiments in which four separate measurements of regional myocardial blood flow were made. At specified times (see below) 600,000-1,000,000 microspheres were injected into the left atrium from a small injection vial with $10 \mathrm{ml}$ of warm saline over a 20-s period. Immediately before the injection, blood was withdrawn at a constant rate of 15 $\mathrm{ml} / \mathrm{min}$ with a small Holter pump into counting vials from a catheter tied in the femoral arteries. During the microsphere injection either three or four 30-s reference blood samples were collected to insure that all the microsphere radioactivity had cleared the dead space of the collecting catheter and none was recirculating. At the end of each experiment the heart was removed and India ink $(0.1 \mathrm{ml})$ was injected to outline the area of ischemia just distal to the proximal left anterior descending coronary artery ligature. This small volume of India ink was used to insure that only the center of the ischemic area was removed and labeled "ischemic area." The atria, epicardial fat, and coronary vessels were removed and the ventricles separated into the right and left ventricular free walls, which were then subdivided into subendocardial, subepicardial, and middle layers of approximately equal thickness. The ventricular septum was subdivided into right and left portions. Ischemic

${ }^{1}$ Abbreviations used in this paper: LAD, left anterior descending coronary artery; $\mathrm{LV}$, left ventricle; $\mathrm{LV} \mathrm{d} p / \mathrm{d} t$ rate of left ventricular pressure rise; $L V \mathrm{~d} p / \mathrm{d} t / p$, maximal rate of left ventricular pressure rise divided by developed LV pressure during isovolumic systole; LVEDP, left ventricular end-diastolic pressure. and nonischemic portions of the left ventricle (LV) were separated. The ischemic area generally represented approximately $25 \%$ of the total weight of the LV. The heart and reference blood samples were placed in glass counting vials and counted in a Nuclear Chicago well gamma scintillation counter (Searle Analytic Inc., Des Plaines, I11.). Regional myocardial blood flow was determined by the method of Rudolph and Heymann (2) modified by using different predetermined constants for differential spectrometry. The total and regional blood flows were computed using the following equation: regional myocardial blood flow equals flow in reference sample (timed volumetric collection from the femoral artery) multiplied by nuclide counts in the myocardial region divided by nuclide counts in the reference sample. Regional coronary blood flows were expressed in milliliters/minute per gram of tissue. Absolute flows and subendocardial/subepicardial (inner/outer) wall flow ratios were determined in ischemic and nonischemic areas.

In addition to regional myocardial blood flow, $\mathrm{LV} \mathrm{d} p / \mathrm{d} t$ was measured before, during, and after each intervention. The experimental format for the anesthetized studies was as follows: The dog was placed on right heart bypass and the rate of pumping into the pulmonary artery adjusted with a Sarns pump (model no. 5M6002 Sarns, Inc., Ann Arbor, Mich.) to provide a cardiac output that did not increase left ventricular end-diastolic pressure (LVEDP) above the normal range. The cardiac output setting was kept constant for the remainder of each individual experiment. Control pressures were measured and ${ }^{225} \mathrm{I}$ was injected into the left atrium to measure control regional myocardial blood flow. 2 min later the proximal left anterior descending coronary artery (LAD) was ligated for a total period of $10 \mathrm{~min}$. At the end of that time pressures and maximal LV d $p / \mathrm{d} t$ and coronary blood flow were measured. The ligation around the LAD was released and the dog placed on total cardiopulmonary bypass for a 30-min recovery period after which he was returned to right heart bypass. The proximal LAD was again ligated 2 min later. A different microsphere was injected after this second period of coronary insufficiency to measure regional myocardial blood flow. By using this experimental format the following studies were performed.

Time-control experiments. Seven dogs were studied in which nothing was infused during the two separate periods of acute coronary insufficiency. These were considered to be "time-related controls" and were done to insure that simply the passage of time did not alter regional myocardial blood flow or ventricular performance in dogs on right heart bypass during repetitive episodes of acute coronary insufficiency.

Preligation infusion studies. 11 Dogs were studied in which $5 \%$ dextrose and water was infused intravenously at $3.82 \mathrm{ml} / \mathrm{min}$ for $30 \mathrm{~min}$ before and throughout the initial period of coronary insufficiency. The glucose infusion was discontinued at the end of the first period of coronary insufficiency. Hypertonic mannitol (25\%) was then infused intravenously before and during the second period of coronary insufficiency at the same rate but for a slightly shorter period of time so that $50 \mathrm{ml}$ less volume of mannitol was infused than dextrose. Although regional myocardial blood flow was measured in all dogs, maximal $\mathrm{LV} \mathrm{d} p / \mathrm{d} t$ was measured in only five.

Postligation infusion studies. In 10 additional dogs 5\% dextrose and water (five studies) or isotonic saline (five studies) was infused intravenously at $7.6 \mathrm{ml} / \mathrm{min}$, the infusion beginning immediately after the onset of the initial 
ligation of the LAD. Each period of acute myocardial ischemia was $12 \mathrm{~min}$ in these experiments.

Hypertonic mannitol was given at the same rate and for the same period of time during a second period of coronary insufficiency in each of these 10 experiments. The control infusion of either $5 \%$ dextrose and water or isotonic saline and the infusion of hypertonic mannitol were considered to be "postligation" infusions in this second set of experiments because increases in osmolality were not achieved until after the proximal LAD had been ligated.

Rapid mannitol infusion studies. Eight dogs were studied by infusing $5 \%$ dextrose and water during the initial period of coronary insufficiency and hypertonic mannitol during the second one. The infusions were begun after LAD ligation at a speed of $15 \mathrm{ml} / \mathrm{min}$

Epicardial mapping in anesthetized dogs with acute myocardial ischemia. Five additional anesthetized dogs (chloralose) were studied during acute myocardial ischemia by utilizing epicardial electrocardiographic mapping. Regional myocardial blood flows were measured by using radioactive microspheres of $9 \mu \mathrm{m}$ in diameter. Endotracheal intubation was achieved and artificial ventilation provided with a Harvard respirator. A median sternotomy was performed and the heart exposed. The LAD was mobilized and a ligature placed around the vessel at its mid level. Three separate 14-min periods of acute myocardial ischemia were provided by ligating the LAD. Epicardial electrocardiograms were obtained before and at the end of each period of coronary insufficiency with a smooth, rounded tip electrode gently applied to each of 14 different sites immediately surrounding the area of LAD ligation (1). Regional myocardial blood flow was measured at the end of each ligation.

Isotonic saline was administered at $7.6 \mathrm{ml} / \mathrm{min}$ with the infusion beginning immediately after ligation of the LAD during the first and last periods of acute coronary insufficiency. Hypertonic mannitol was infused at the same speed during the second period of coronary insufficiency. Systemic arterial pressures and $\mathrm{LV} \mathrm{d} p / \mathrm{d} t$ and coronary flow were measured as described earlier. In these experiments the $0.7-\mathrm{cm}$ portion of myocardium immediately adjacent to the ischemic portion of the $L V$ was removed and counted separately from the ischemic and nonischemic portions of the LV. This area is subsequently referred to as the "periischemic portion" of the LV This was the only group of experiments in which a periischemic region was separated and counted separately from the remainder of the nonischemic region of the LV.

\section{Conscious, intact dog studies}

Adult mongrel dogs of either sex were anesthetized with sodium pentothal $(60 \mathrm{mg} / \mathrm{kg})$ and artificial ventilation provided with endotracheal intubation and a Harvard respirator. The heart was exposed through a left thoracotomy. The LAD was mobilized between 2 and $3 \mathrm{~cm}$ from its origin and an inflatable silicone rubber balloon with a silastic backing sutured around the artery at that level. The tube from this balloon was exteriorized by bringing it through the skin behind the animal's neck. Preliminary studies were performed in each dog at the time of insertion of the balloon device to determine what volume of saline should be added to the balloon to fully inflate it and totally occlude the underlying coronary artery. This same balloon occlusive cuff has previously been used by others to provide acute coronary insufficiency in the dog $(3,4)$. Atrial pacing electrodes were attached to the left atrium and ventricular electrodes to the right ventricle. The atrial and ventricular pacing electrodes were implanted and one or the other was subsequently utilized to provide a constant heart rate at the time of the experimental study. A Konigsberg pressure transducer (model P21, Konigsberg Instruments, Inc., Pasadena, Calif.) was positioned in the LV and its distal end exteriorized. The pericardium was loosely resutured. A left atrial catheter was also positioned, stabilized, and exteriorized. Teflon-coated catheters were placed in the left carotid artery and external jugular vein. All of these catheters were periodically filled with small amounts of heparin. The catheters were covered with a sleeve and tape to protect them.

These dogs were studied no sooner than 2 wk postoperatively at a time when they appeared to have fully recovered from the previous instrumentation. They were trained in the study area to lie quietly in support slings. All animals appeared relaxed in the sling during the study period. Atrial pacing electrodes were connected to a Grass stimulator (model S88, Grass Instrument Co., Quincy, Mass.) and the dogs paced at a rate $15-20$ beats/min above their own intrinsic heart rate throughout the study. These heart rates ranged from 90 to 150 beats $/ \mathrm{min}$. Systemic arterial, left ventricular pressures and maximal LV $\mathrm{d} p / \mathrm{d} t$ and myocardial flows were measured in the resting state. Cardiac outputs were measured by the green dye technique (Physiotronics densitometer, Burbank, Calif., model DDCCO-O). Blood samples were obtained for hematocrit, gases, and osmolality after each intervention. These animals were studied in a fully conscious state without having received any sedation. The studies followed the format described below.

(a) Acute myocardial ischemia studies. After the control measurements of pressures, cardiac output, and regional myocardial blood flow the balloon occlusive device was inflated to its maximal volume over a 5-min period in 11 dogs. Isotonic saline was infused at $7.6 \mathrm{ml} / \mathrm{min}$ for the first $15 \mathrm{~min}$ and at $3.82 \mathrm{ml} / \mathrm{min}$ for the remaining $5 \mathrm{~min}$. The infusion was begun immediately after the onset of initiating balloon occlusion. Pressures, cardiac output, and regional myocardial blood flow measurements were repeated again at the end of the 15-min period of occlusion. The balloon occlusive device was then deflated and a 30 -min rest period allowed. Next a second period of coronary insufficiency was provided except that hypertonic mannitol was infused rather than isotonic saline. The same parameters were measured before and at the end of the second period of coronary insufficiency. The balloon occlusive device was then again deflated. Several hours after the conclusion of this study a final experiment was obtained in four animals in which isotonic saline was infused and the remainder of the experiment repeated just as before. At the conclusion of the complete set of experiments the animal was sacrificed, the heart removed, and a postmortem coronary arteriogram obtained with the balloon fully inflated. This was done to insure that the balloon occlusive device did fully occlude the proximal LAD when fully inflated. The pressure used to perform the postmortem coronary arteriogram was one in excess of $100 \mathrm{~mm} \mathrm{Hg}$. In each of the 11 experiments reported there was complete occlusion of the proximal LAD at the site of the inflated balloon. The heart was then sectioned for microsphere counting as described earlier.

(b) Chronic myocardial ischemia studies. In nine additional dogs the same experiment format was followed except that the balloon occluder was inflated and not subsequently deflated so as to produce a myocardial infarction over 48-72 h. 48-72 $\mathrm{h}$ after the initial LAD occlusion the animal was placed in the support sling for study. Isotonic saline was 
TABLE I

Influence of Two Serial Ligations of the LAD on Regional Myocardial Blood Flow and Ventricular Performance in Anesthetized Dogs $(n=7)$

\begin{tabular}{|c|c|c|c|c|c|c|c|}
\hline Condition & MAP & LVEDP & $L V \mathrm{~d} p / \mathrm{d} t$ & RV & vs & LVAT & LVCT \\
\hline & $m m H g$ & $m m \mathrm{Hg}$ & $m m H g / s$ & $\mathrm{ml} / \mathrm{min} / \mathrm{g}$ & $\mathrm{ml} / \mathrm{min} / \mathrm{g}$ & $\mathrm{ml} / \mathrm{min} / \mathrm{g}$ & $m l / m i n / g$ \\
\hline Control & 50 & 6.5 & 1,150 & 0.34 & 0.84 & 0.74 & 0.84 \\
\hline Initial ligation & 70 & 10.5 & 1,000 & 0.36 & 0.97 & 0.18 & 1.07 \\
\hline Second ligation & 70 & 11.5 & 1,050 & 0.51 & 1.19 & 0.22 & 1.30 \\
\hline Control & 80 & 9.0 & 1,700 & 0.71 & 0.91 & 0.92 & 0.85 \\
\hline Initial ligation & 103 & 7.0 & 1,900 & 0.60 & 1.09 & 0.66 & 1.15 \\
\hline Second ligation & 115 & 10.0 & 2,200 & 0.78 & 0.96 & 0.49 & 1.04 \\
\hline Control & 63 & 6.0 & 1,500 & 0.32 & 0.77 & 0.65 & 0.67 \\
\hline Initial ligation & 70 & 11.0 & 1,600 & 0.43 & 0.82 & 0.20 & 0.90 \\
\hline Second ligation & 78 & 15.0 & 1,700 & 0.39 & 0.65 & 0.16 & 0.80 \\
\hline Control & 73 & 3.0 & 2,600 & 0.59 & 0.88 & 0.65 & 0.67 \\
\hline Initial ligation & 82 & 4.0 & 2,200 & 0.46 & 0.66 & 0.34 & 0.77 \\
\hline Second ligation & 80 & 6.0 & 2,000 & 0.52 & 0.92 & 0.31 & 0.82 \\
\hline Control & 68 & 7.0 & 1,500 & 0.39 & 0.62 & 0.72 & 0.67 \\
\hline Initial ligation & 58 & 9.0 & 2,000 & 0.35 & 0.54 & 0.27 & 0.63 \\
\hline Second ligation & 65 & 8.0 & 1,800 & 0.41 & 0.68 & 0.31 & 0.72 \\
\hline Control & 75 & 11.0 & 2,400 & 0.55 & 1.04 & 0.96 & 0.81 \\
\hline Initial ligation & 85 & 8.0 & 2,400 & 0.54 & 1.01 & 0.41 & 0.94 \\
\hline Second ligation & 93 & 8.0 & 2,400 & 0.56 & 0.95 & 0.34 & 0.82 \\
\hline Control & 75 & 8.0 & 2,600 & 0.35 & 0.69 & 0.77 & 0.74 \\
\hline Initial ligation & 110 & 13.0 & 2,500 & 0.34 & 0.71 & 0.54 & 0.87 \\
\hline Second ligation & 110 & 20.0 & 2,500 & 0.40 & 0.83 & 0.59 & 0.95 \\
\hline \multicolumn{8}{|l|}{ Mean } \\
\hline Control & $69 \pm 3.8(\mathrm{SE})$ & $7 \pm 0.9$ & $1,921 \pm 226.2$ & $0.46 \pm 0.06$ & $0.82 \pm 0.05$ & $0.77 \pm 0.05$ & $0.75 \pm 0.03$ \\
\hline Initial ligation & $83 \pm 7.1$ & $9 \pm 1.1$ & $1,942 \pm 195.0$ & $0.44 \pm 0.04$ & $0.83 \pm 0.08$ & $0.37 \pm 0.07$ & $0.90 \pm 0 t 07$ \\
\hline Second ligation & $87 \pm 7.3$ & $11 \pm 1.8$ & $1,950 \pm 186.8$ & $0.51 \pm 0.05$ & $0.88 \pm 0.07$ & $0.35 \pm 0.06$ & $0.92 \pm 0.07$ \\
\hline
\end{tabular}

LVAT, flow to ischemic area of LV; LVCT, flow to nonischemic area of LV; MAP, mean arterial blood pressure; RV, flow to right ventricle; VS, flow to ventricular septum.

infused intravenously at $7.6 \mathrm{ml} / \mathrm{min}$ for a 12 -min period and regional myocardial blood flow, pressures, and cardiac output were measured. A 20 -min rest period was provided and then hypertonic mannitol infused at the same rate and for the same period of time. Pressures and cardiac output were recorded and myocardial blood flow measured. In three animals, a final series of pressure and regional myocardial blood flow measurements were made $1 \mathrm{~h}$ later associated with another infusion of isotonic saline. In all except two of the nine dogs studied there was both gross and microscopic evidence of myocardial infarction.

In five additional dogs with LAD occlusion for $48 \mathrm{~h}$ three separate measurements of regional myocardial blood flow were made as a control for the above studies. The three separate flow measurements were made at 30 -min intervals.

A paired $t$ test was used to compare the differences between interventions in each animal that was studied. Least squares regression analyses were performed for certain comparisons (see Results section) and a Pearson product moment correlation coefficient computed. ${ }^{2}$ The results were considered of statistical significance when $P<0.05$.

\section{RESULTS}

Time-related controls for anesthetized acute coronary insufficiency studies. Regional myocardial blood flow did not change significantly with the two separate ligations of the proximal LAD in any portion of the LV (Table I). However, flow to the right ventricle was significantly greater $(15.8 \pm 8.32 \%)$ during the second ligation than the first in these animals on right heart bypass $(P<0.05)$.

There were no significant changes in hemodynamics, hematocrit, or osmolality between the two separate pe-

${ }^{2}$ Statistical assistance was provided by Dr. Richard Browne of the University of Texas (Southwestern) Medical Center Computer Dept. 


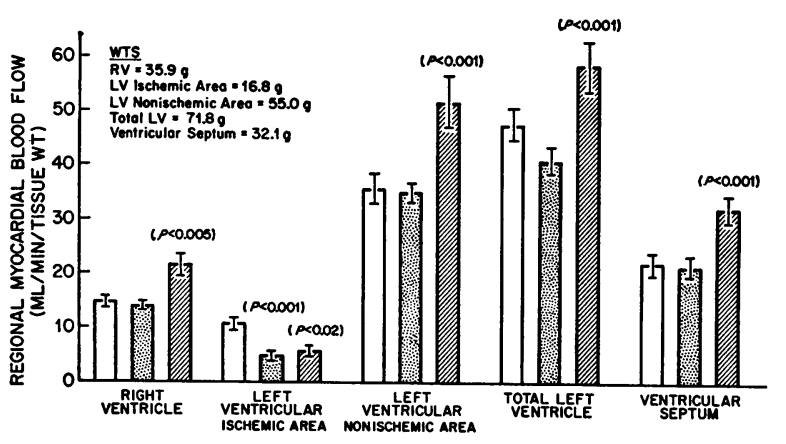

FIgURE 1 The increases in regional myocardial blood flow after mannitol, which was given before and during acute coronary insufficiency $(n=11)$. Note that coronary flow increased after mannitol in all portions of the heart including the ischemic area. Open bars, initial control; stippled bars, initial period of acute coronary insufficiency; hatched bars, second period of acute coronary insufficiency with mannitol begun before coronary occlusion. $P$ values refer to comparisons between each intervention and the one immediately preceding it.

riods of LAD ligation in the control studies. LVEDP and mean aortic pressure both tended to increase (increases of $19.7 \pm 8.6 \%[\mathrm{SE}]$, and $5.2 \pm 2.25 \%$, respectively, $P=0.06$ ) while maximal $\mathrm{LV} \mathrm{d} p / \mathrm{d} t$ remained unchanged $(1.2 \pm 3.4 \%$ ( Table I).

Preligation mannitol infusion studies in anesthetized dogs. Regional myocardial blood flow to the portion of the LV supplied by the occluded LAD fell by 55士 $7.47 \%$ (SE) $(P<0.001)$ during the initial ligation (Fig. 1). Mannitol significantly increased flow to this area by $30.1 \pm 11.58 \%(P<0.02)$ over that present during the first ligation (Fig. 1). Mannitol did not change the inner:outer wall ratio in either these experiments or in any of those that follow. Mannitol administration also significantly increased flow during acute coronary insufficiency (compared to the initial period of acute coronary insufficiency without mannitol) to the ventricular septum $(47.5 \pm 12.22 \%, P<0.001)$, the nonischemic portion of the LV $(46.4 \pm 10.15 \%, P<$ $0.001)$, and to the right ventricle $(53.3 \pm 11.16 \%, P<$ 0.005 ) (Fig. 1). The increase in flow to the right ventricle in these dogs after mannitol was significantly greater than occurred in the time-related control experiments $(P<0.05)$. The increase in flow to the ischemic region after mannitol appeared to be similar to that noted in the nonischemic portion of the LV (Fig. 2).

Maximal LV $\mathrm{d} p / \mathrm{d} t$ tended to increase during the period of acute coronary insufficiency associated with the mannitol infusion, but the change was not of statistical significance in the five animals in this group in whom LV $\mathrm{d} p / \mathrm{d} t$ was measured (Table II). The increase in flow to the LV after mannitol appeared to be more remarkable than the increase in contractility
(Fig. 3). Neither LVEDP nor mean arterial pressure changed significantly in these experiments (Table II). Serum osmolality increased $28 \mathrm{mosmol} / \mathrm{kg}(P<0.01)$ and serum hematocrit tended to fall after mannitol (Table II).

Postocclusion mannitol infusion studies in anesthetized dogs. The directional changes in regional myocardial blood flow were identical whether isotonic saline or $5 \%$ dextrose and water was used; therefore, these were combined to serve as a control reference for the mannitol infusion studies. In these experiments regional myocardial blood flow to the ischemic portion of the LV fell $48.6 \pm 10.24 \%(P<0.005)$ during the initial ligation, whereas, mannitol increased flow to this area by $35.8 \pm 8.99 \%(P<0.01)$ during acute myocardial ischemia (Fig. 4). Mannitol also significantly increased flow to the nonischemic LV by $21.2 \pm 8.79 \%$ $(P<0.05)$, to the ventricular septum by $29.3 \pm 10.02 \%$ $(P<0.02)$, and to the right ventricle by $35.6 \pm 16.69 \%$ $(P<0.05)$ during acute myocardial ischemia (Fig. 4). The increase in flow to the right ventricle after mannitol in these experiments, however, was not signifi-

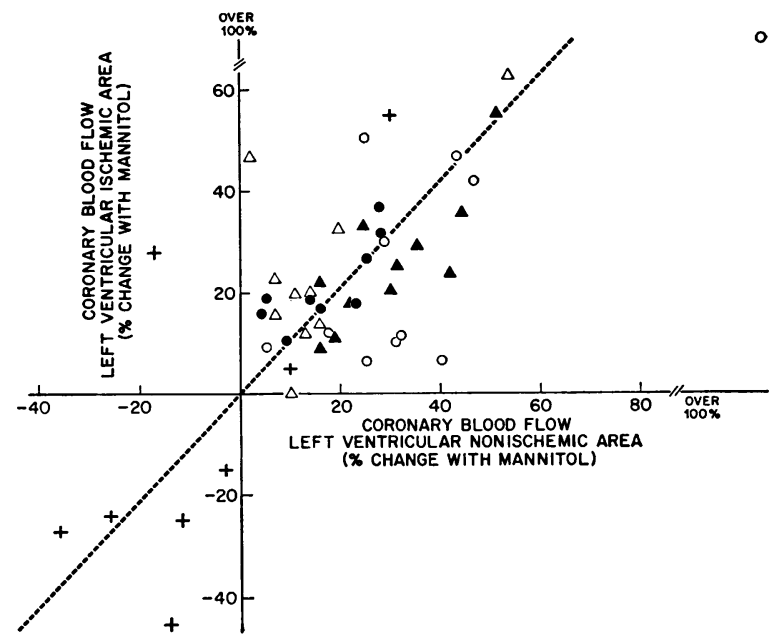

FIgURE 2 Mannitol in dogs with LAD occlusion. The changes in coronary blood flow after mannitol in the ischemic region of the $\mathrm{LV}$ are plotted on the vertical axis and those in the nonischemic portion of the LV on the horizontal one. All of the different experimental models studied are shown in this figure. The dotted line is a line of identity. The open circles represent the studies of acute coronary insufficiency done in the awake, unsedated dogs; the closed circles those done in awake dogs with myocardial infarction. The open triangles represent the studies done in anesthetized dogs given mannitol after the LAD occlusion; the closed triangles the studies done in anesthetized dogs given mannitol before and during the LAD occlusions. The cross represents the rapid infusion of mannitol studies done in anesthetized dogs. The formula for relating the total observations to one another is: left ventricular ischemic area flow $=3.233+0.895$ ( $\mathrm{LV}$ nonischemic area flow), $r$ $=0.687, P<0.001$. 
TABLE II

Hemodynamic Changes in the Different Animal Models Studied After Mannitol

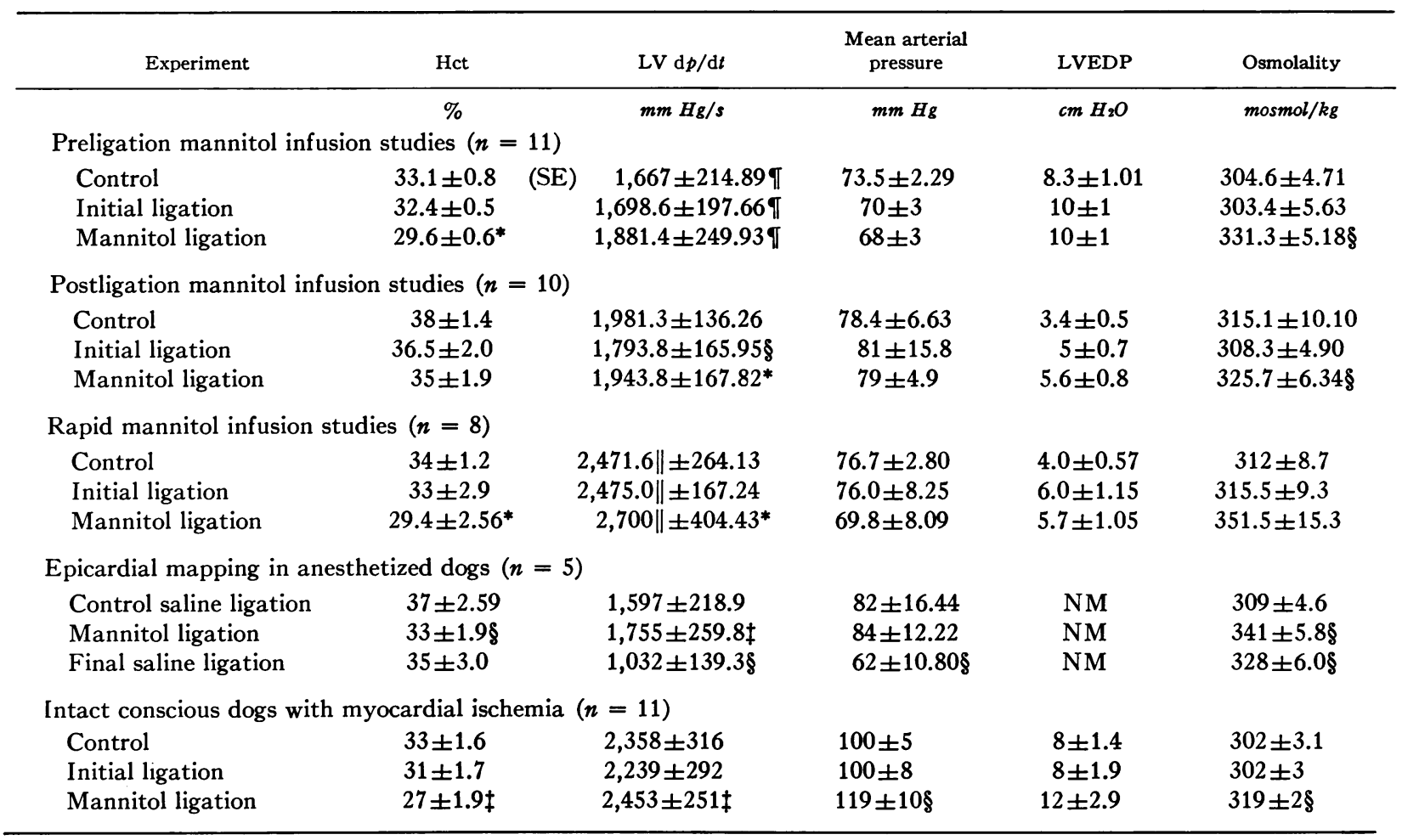

Statistical comparisons are made between each listed value and the one immediately above it. NM, not measured.

$* P<0.1$.

$\ddagger P<0.05$.

$\S P<0.01$.

|| Measurements made in only six dogs.

Tा Measurements made in only five dogs.

cantly greater than that noted in the time-related controls (grouped mean comparisons). The increases in flow to the ischemic portion of the $\mathrm{LV}$ after mannitol appeared to be just as great as the increases in flow to the nonischemic left ventricle (Fig. 2).

Maximum $\mathrm{LV} \mathrm{d} p / \mathrm{d} t$ tended to increase during the period of coronary insufficiency associated with the administration of mannitol $(10 \pm 3.6 \%, P<0.05)$ (Table II.) There was no significant change in mean arterial pressure, LVEDP, nor hematorcrit during coronary insufficiency after mannitol (Table II). Mannitol increased serum osmolality $17 \mathrm{mosmol} / \mathrm{kg}$. In these experiments the increases in LV flow after mannitol were more impressive than the changes in contractility (Fig. 3).

Rapid infusion of mannitol studies in anesthetized dogs. In eight dogs hypertonic mannitol was infused at $15 \mathrm{ml} / \mathrm{min}$ immediately after the onset of ligation of the LAD. In these experiments regional myocardial blood flow tended to fall or remain the same rather than increase after mannitol in all areas (Fig. 5).
Mannitol tended to produce a slight increase in LV $\mathrm{d} p / \mathrm{d} t$ (Table II). Mean aortic pressure and LVEDP were not significantly changed by mannitol (Table II). Mannitol increased serum osmolality by $36 \mathrm{mosmol} / \mathrm{kg}$ $(P<0.01)$, while tending to decrease hematocrit (Table II).

Epicardial mapping in anesthetized dogs with acute myocardial ischemia. These studies were done to determine if the increases in flow to the ischemic area after mannitol were associated with epicardial electrocardiographic evidence for reduction in the area of ischemic injury. The epicardial ST segment mapping results are shown in Fig. 6. Mannitol reduced ST segment elevation by $41.5 \pm 5.70 \%$ during acute myocardial ischemia while increasing regional myocardial blood flow to the ischemic area by $51.4 \pm 16.06 \%(P<0.01)$, to the periischemic area by $69.2 \pm 24.92 \%(P<0.01)$, to the ventricular septum by $70.8 \pm 14.86 \%(P<0.005)$, to the nonischemic area of the LV by $52.5 \pm 10.42 \%$ $(P<0.005)$, and to the right ventricle by $55.8 \pm$ $11.52 \%(P<0.01)$. Regional myocardial blood flow 


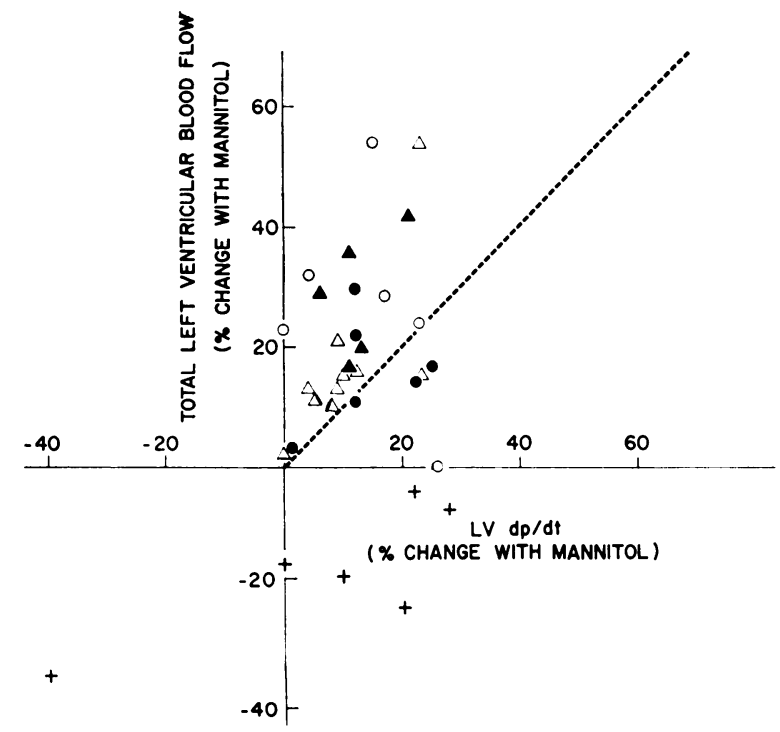

FIgure 3 Mannitol in dogs with LAD occlusion. The changes in total left ventricular blood flow after mannitol are plotted on the vertical axis and those in maximal LV $\mathrm{d} p / \mathrm{d} t$ on the horizontal one. Observations made in each of the different models studied are shown. The symbols for the different models are the same as identified in Fig. 2. The dotted line is a line of identity. The formula relating the changes is total LV flow $=6.95+0.256(\mathrm{LV} \mathrm{d} p / \mathrm{d} t), r$ $=0.375, P<0.03$.

fell in the four animals in whom flow measurements were made during the third period of coronary insufficiency decreasing by $58.0 \pm 15.87 \%$ to the ischemic area $(P<0.05), 52.5 \pm 10.42 \%$ to the nonischemic area $(P<0.01), 52.0 \pm 10.91 \%(P<0.01)$ to the ventricular septum, and $55.7 \pm 11.5 \%$ to the right ventricle $(P<$ 0.01 ) as compared to those present after mannitol. As in the previous studies done in anesthetized dogs, man-

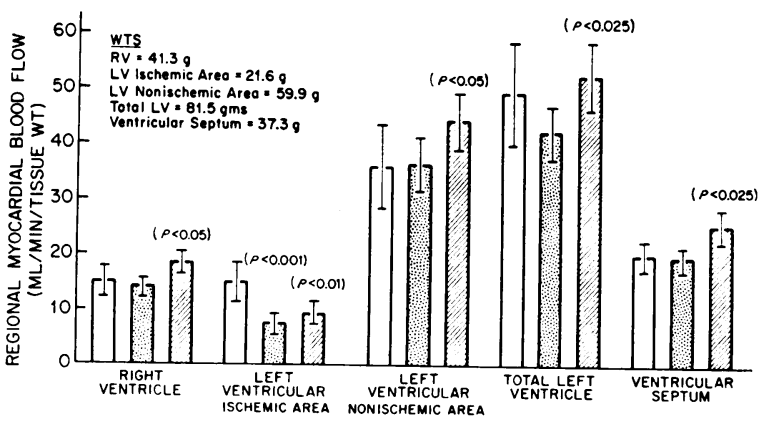

FIGURE 4 The increases in regional myocardial blood flow after mannitol with the mannitol infusion beginning immediately after ligation of the proximal LAD $(n=10)$. Open bars, initial control; stippled bars, initial period of acute coronary insufficiency; hatched bars, second period of acute coronary insufficiency with mannitol begun after coronary occlusion.

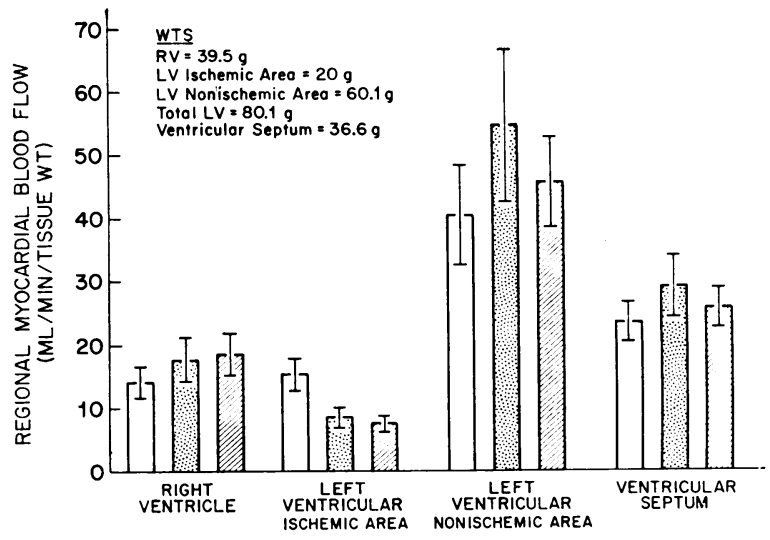

FIGURE 5 The failure of mannitol to increase regional myocardial blood flow when administered at $15 \mathrm{ml} / \mathrm{min}$ with the infusion beginning immediately after LAD occlusion $(n=$ 8). Open bars, initial control; stippled bars, initial period of acute coronary insufficiency; hatched bars, second period of acute coronary insufficiency with mannitol infusion.

nitol did not significantly increase mean arterial pressure but did increase maximal $\mathrm{LV} \mathrm{d} p / \mathrm{d} t$ (Table II). Hematocrit decreased and osmolality increased significantly after mannitol (Table I).

Intact, conscious dogs with acute myocardial ischemia. In the 11 studies done in awake, unsedated dogs, hypertonic mannitol increased regional myocardial blood flow (Fig. 7). During the control ligation regional myocardial blood flow to the ischemic area of the LV fell by $27.6 \pm 9.28 \%(P<0.05)$. Mannitol increased flow to this area by $27.2 \pm 11.40 \% \quad(P<0.05)$ during coronary insufficiency compared to the initial ligation flow. Mannitol also increased flow to the nonischemic portion of the LV by $29.4 \pm 12.3 \%(P<0.05)$, to the ventricular septum by $41.1 \pm 16.0 \%(P<0.05)$, and to the right ventricle by $39.1 \pm 16.0 \% \quad(P<0.05)$. The increase in flow to the ischemic portion of the LV after mannitol appeared to be just as impressive as that occurring in the nonischemic LV (Fig. 2). In four of the 11 experiments a final isotonic saline infusion study was obtained several hours after the mannitol experiment. In all four of these experiments regional flow to the left ventricular ischemic area was lower than it had been during the preceding mannitol study (mean reduction $4.2 \mathrm{ml} / \mathrm{min} /$ tissue $\mathrm{wt}$ ).

Although mean systemic arterial blood pressure did not change during acute coronary insufficiency associated with the initial isotonic saline infusion it was significantly increased by mannitol $(100 \pm 7 \mathrm{~mm} \mathrm{Hg}$ preligation to $119 \pm 10 \mathrm{~mm} \mathrm{Hg}, P<0.01$ ) (Table II). LVEDP did not change significantly during the initial saline, the mannitol, or the final saline infusion (Table II). There was no significant change in maximum LV $\mathrm{d} p / \mathrm{d} t$ or $\mathrm{LV} \mathrm{d} p / \mathrm{d} t$ divided by developed LV pressure 
during isovolumic systole $(\mathrm{d} p / \mathrm{d} t / p)$ during the first peiod of coronary insufficiency. Maximal left ventricular $\mathrm{d} p / \mathrm{d} t$ and $d \mathrm{p} / d t / p$ did, however, increase significantly with mannitol $(2,099 \pm 263$ to $2,453 \pm 251 \mathrm{~mm} \mathrm{Hg} / \mathrm{s}, P<$ 0.05 ; and $26.2 \pm 4$ to $29.6 \pm 4.1 / \mathrm{s} P<0.05)$. The increases in flow to the $\mathrm{LV}$ after mannitol appeared to be more impressive than the increases in contractility (Fig. 3). Cardiac output did not change significantly during any of the different interventions ( $3.2 \pm 0.3$ to $3.0 \pm 0.3 \mathrm{liter} / \mathrm{min}$ initial saline, $2.6 \pm 0.3$ to $2.7 \pm 0.4$ liter/min during final saline, and $3.1 \pm 0.4$ to $3.2 \pm 0.4$ liter/min after mannitol). Hematocrit fell slightly but significantly during mannitol from $31 \pm 1.5$ to $27.3 \pm$ $1.9 \%(P<0.01)$.

Intact conscious dogs with chronic myocardial ischemia and myocardial infarction. Mannitol given to increase serum osmolality $20 \mathrm{mosmol} / \mathrm{kg}$ increased regional myocardial blood flow to the area of infarction by $22 \pm 2.8 \% \quad(1.06 \pm 0.19$ to $1.36 \pm 0.23 \mathrm{ml} / \mathrm{min} / \mathrm{g}, P<$ $0.01)$. Mannitol also significantly increased regional flow to the nonischemic area by $12 \% \quad(1.44 \pm 0.14$ to $1.61 \pm 0.15 \mathrm{ml} / \mathrm{min} / \mathrm{g}(P<0.01)$ and to the ventricular septum by $16 \% \quad(1.38 \pm 0.15$ to $1.60 \pm 0.16 \mathrm{ml} / \mathrm{min} / \mathrm{g}, P$ $<0.025)$. Regional flow to the right ventricle after mannitol also tended to increase but the change was not significant $(0.81 \pm 0.14$ to $0.92 \pm 0.12 \mathrm{ml} / \mathrm{min} / \mathrm{g})$.

The increases in flow to the ischemic region of the $\mathrm{LV}$ after mannitol appeared to be just as great as the increases in flow to the nonischemic LV (Fig. 2). In the five control dogs with LAD occlusion for $48 \mathrm{~h}$ in whom serial measurements of regional myocardial blood flow were made, there was no significant change in flow to any portion of the $\mathrm{LV}$ between the first and second or second and third measurements.

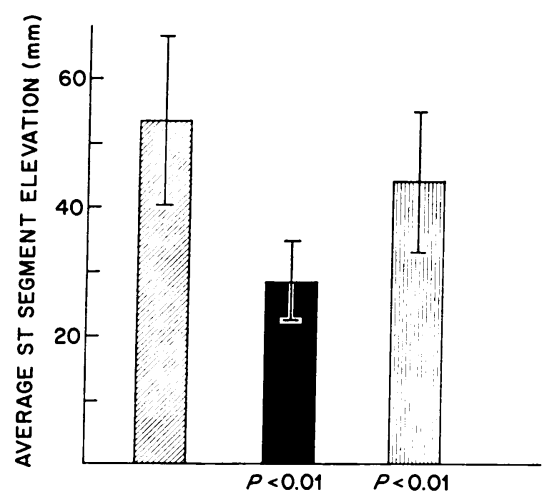

FIgURE 6 The reduction in epicardial ST segment elevation during acute myocardial ischemia associated with the administration of mannitol. Average ST segment elevation is total mean ST segment elevation that occurred in the five dogs studied. Obliquely hatched bar, initial coronary insufficiency with saline; filled bar, coronary insufficiency with mannitol; vertically hatched bar, final coronary insufficiency with saline.

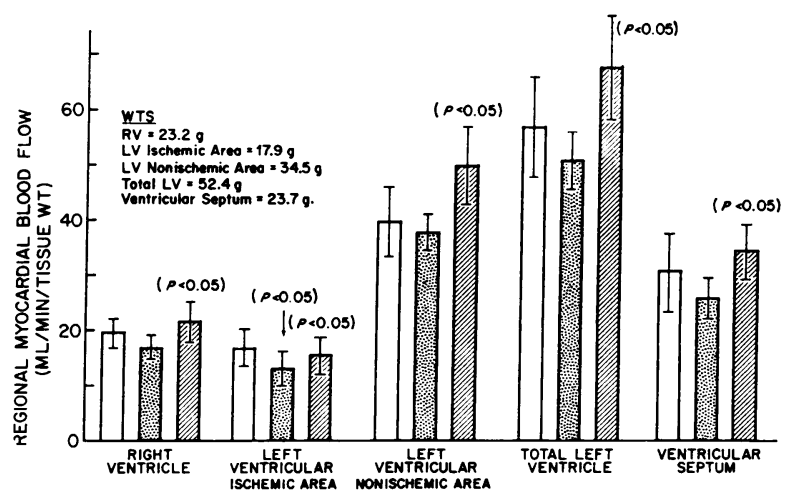

Figure 7 The increases in regional myocardial blood flow after mannitol in awake, unsedated dogs with acute myocardial ischemia $(n=11)$. Open bars, initial period; stippled bars, initial period of acute coronary insufficiency; hatched bars, second period of coronary insufficiency with mannitol began after coronary occlusion.

Mannitol also significantly increased mean arterial pressure by $14 \%$ ( $114 \pm 3$ to $131 \pm 8 \mathrm{~mm} \mathrm{Hg}, P<0.01$ ), $\mathrm{LV} \mathrm{d} p / \mathrm{d} t$ by $18 \%(1,993 \pm 127$ to $2,358 \pm 136 \mathrm{~mm} \mathrm{Hg} / \mathrm{s}$, $P<0.001)$, and cardiac output by $15 \% \quad(2.6 \pm 0.2$ to $3.0 \pm 0.2 \mathrm{liter} / \mathrm{min}, P<0.002$ ) in these experiments. The increases in flow to the $\mathrm{LV}$ after mannitol appeared to be more impressive than the increases in contractility (Fig. 3). Mannitol did not significantly change LVEDP ( $6 \pm 2$ to $10 \pm 2 \mathrm{~cm} \mathrm{H}_{2} \mathrm{O}$ ) but did slightly decrease hematocrit $(33 \pm 2$ to $31 \pm 2 \%, P<0.05)$. Saline did not significantly change any parameter of ventricular performance, osmolality, or hematocrit.

\section{DISCUSSION}

In this study the right bypass preparation was used to keep cardiac output, heart rate, and mean arterial pressure constant in the anesthetized dogs. Awake, intact dogs were used to study the influence of hypertonic mannitol under conditions in which neither anesthesia nor sedation was used. The ischemic area was defined by that area of myocardium stained by $0.1 \mathrm{ml}$ of India ink injected immediately distal to the proximal LAD to insure that just the center of the ischemic area was removed and counted as "ischemic area." The marked reduction in regional myocardial blood flow to this area during the initial occlusion provides evidence that it was appropriate to consider this area ischemic. A $0.7-\mathrm{cm}$ myocardial strip immediately adjacent to the area considered ischemic was also obtained in some of the anesthetized dogs experiments. This was considered the "periischemic area" and it was studied to be certain that the changes in ischemic area flow were similar to those noted in periischemic and as well as in nonischemic regions. The measurement of regional myocardial blood flow using radioactive microspheres in these 
studies was accomplished without changing hemodynamic conditions and without noticeably disturbing even the awake, unsedated dogs.

The data obtained in this study demonstrate that hypertonic mannitol increases regional myocardial blood flow during acute myocardial ischemia in anesthetized dogs and during acute myocardial ischemia and chronic myocardial infarction in awake, unsedated dogs. Myocardial blood flow increased in the ischemic and nonischemic portions of the $\mathrm{LV}$, the ventricular septum, and the right ventricle in the anesthetized dogs given mannitol both before and after LAD occlusion. In awake, unsedated dogs with acute and chronic myocardial ischemia coronary blood flow increased after mannitol infusion to the ischemic and nonischemic portions of the $\mathrm{LV}$ and to the ventricular septum. There was also a tendency for regional flow to the right ventricle to increase but the changes were not statistically significant. The relatively small decrease in flow to the ischemic portion of the $\mathrm{LV}$ in the awake dogs with acute myocardial ischemia may be an indication that there was partial premature occlusion resulting from direct trauma and/or the development of scar tissue at the site of the occluder. This then might have initiated increased collateral vessel supply so that when the occlusion was subsequently applied relatively small reductions in flow occurred in these animals. The changes in regional myocardial blood flow in these studies after mannitol are somewhat less impressive than those described earlier when isolated, perfused canine hearts were used and krypton-85 was used to measure collateral coronary blood flow (1). These differences might conceivably be explained by the different preparations studied (isolated, perfused canine heart versus anesthetized, open-chest or awake, unsedated, closed-chest dog) and/or by the different methods used to measure collateral coronary blood flow (krypton-85 versus radioactive microspheres).

The reduction in epicardial ST segment elevation during acute myocardial ischemia in anesthetized dogs after mannitol suggests that at least under these circumstances the increases in regional myocardial blood flow to the ischemic and periischemic regions reduce the extent of myocardial ischemia. It should be noted, however, that the increases in regional myocardial blood flow after mannitol in the dogs that had epicardial ST segment mapping were somewhat greater than those that occurred in the other anesthetized dog studies, probably resulting from the fact that mannitol increased serum osmolality more than noted in the other studies. Epicardial sites of ST segment elevation are known to be sites of subsequent cell death (5), anaerobic metabolism, and both epicardial and subendocardial ischemia (6). Some caution has to be exerted, however, in interpreting epicardial ST segment mapping results since recently concern has been expressed that epicardial ST segments may not be an adequate indicator of changes in the degree of subendocardial ischemia during prolonged coronary occlusion (7).

In addition to bringing about the changes in regional myocardial blood flow mannitol tended to increase maximal LV d $p / \mathrm{d} t$ during acute myocardial ischemia in the anesthetized animals and did increase maximal LV $\mathrm{d} p / \mathrm{d} t$ and $\mathrm{d} p / \mathrm{d} t / p$ in the awake, unsedated dogs. There were no significant changes in LVEDP after mannitol, but mean arterial pressure did increase significantly in the awake dogs. However, the changes in flow to the $\mathrm{LV}$ after mannitol appeared to be more impressive than the changes in contractility in all of the different models that were studied.

The fact that myocardial blood flow increased while there were only small and not always significant changes in hematocrit indicates that the changes in flow after mannitol were almost certainly not due to the small changes in hematocrit. Neither can increases in regional myocardial blood flow after mannitol be attributed to changes in cardiac output, systemic arterial blood pressure, or heart rate in the anesthetized dogs since these parameters were held constant. In addition, there was no predictable relationship in individual animals between the magnitude or the direction of the change in flow and that noted in contractility after mannitol (Fig. 3). This strongly suggests that the change in contractility after mannitol was not solely responsible for the increase in coronary blood flow. It seems likely that the increases in regional myocardial blood flow after mannitol in the anesthetized dogs occurred at least in part as the result of a reduction in coronary vascular resistance directly attributable to hypertonic mannitol. This is probably a direct effect of hyperosmolality on smooth muscle coronary vascular resistance and not just the effect of mannitol to improve capillary flow by reducing cell swelling since the models in which cell swelling have been demonstrated in other studies required longer periods of ischemia than $10 \mathrm{~min}$ to become detectable (8-10). In addition the increases in regional myocardial blood flow to nonischemic portions of the LV after mannitol are presumably not due to or dependent upon mannitol's ability to alter cell swelling since cell swelling should not have occurred in these areas. The very close correlation between the change in coronary flow in both ischemic and nonischemic LV after mannitol suggests that the same mechanism may be responsible for the change in flow in both areas. However, it is possible that mannitol increased regional flow to the nonischemic portion of the LV by reducing endothelial and/or interstitial cell size in nonswollen cells thus reducing intravascular and extravascular resistance to flow. In the awake, unsedated dogs the increases in regional myocardial flow are probably the 
result of a combination of factors, including an increase in mean arterial blood pressure, enhanced contractile state, and a direct effect of hyperosmolality to extrinsically or intrinsically reduce coronary vascular resistance in both ischemic and nonischemic LV.

Others have previously demonstrated that hypertonic mannitol reduces renal (11) and pulmonary vascular resistance (12). Hyperosmolar solutions have also been shown to decrease coronary vascular resistance in anesthetized dogs without myocardial ischemia (13) and limb vascular resistance in humans (14).

It was of interest to find in the present studies that a rapid infusion rate of hypertonic mannitol $(15 \mathrm{ml} /$ min) decreased or did not change regional myocardial blood flow. Under these same conditions LVEDP did not change and maximal $\mathrm{LV} \mathrm{d} p / \mathrm{d} t$ tended to increase. This suggests that too rapid local increases in osmolality may actually increase coronary vascular resistance while still exerting the same inotropic effect. This again appears to indicate that the change in contractility after mannitol is not solely responsible for the change in coronary blood flow. In other studies we have found that similar osmolality elevations as were noted in these experiments, i.e. $40 \mathrm{mosmol} / \mathrm{kg}$ above control, achieved with slower infusion rates of mannitol increase regional myocardial flow (15). This also implies that the changes in regional coronary blood flow may not be totally responsible for the inotropic effect of hypertonic mannitol in anesthetized dogs and demonstrates that rapid local increases in osmolality may produce different effects on coronary vascular smooth muscle than on myocardial cells. Hypertonic agents have been previously shown to exert a direct inotropic effect in isolated, isometrically contracting, well-oxygenated, and in hypoxic cat right ventricular papillary muscles (16, 17). This direct inotropic effect in isolated cat papillary muscles is, of course, independent of changes in blood flow and appears to be importantly related to intracellular calcium regulation (18).

In summary, the data from these experiments suggest that hypertonic mannitol increases regional myocardial blood flow during acute myocardial ischemia in anesthetized dogs and during acute myocardial ischemia and myocardial infarction in awake, unsedated ones. The increases are generalized ones and include significant increases in flow to the ischemic or infarcted area of the LV. The increases in regional myocardial blood flow to the ischemic area appear to be similar in magnitude to the increases in flow to the nonischemic portion of the LV. These changes in regional myocardial flow occur irrespective of whether mannitol is given before or after ligation of the LAD. The increases in regional myocardial blood flow after mannitol are associated with reductions in epicardial ST segment elevation in anesthetized open-chest dogs during acute myo- cardial ischemia suggesting that, at least under certain circumstances, the increases in regional flow are of physiological importance in reducing the extent of myocardial injury. The general increases in regional myocardial flow after mannitol during acute myocardial ischemia noted in this study cannot be adequately explained solely on the basis of alterations in ischemic cell swelling. The data obtained in these studies suggest the need for a careful assessment of the efficacy of hyperosmolar mannitol in similar clinical settings.

\section{ACKNOWLEDGMENTS}

The authors wish to express their appreciation to Miss Judy Ober, Mr. Robert Wiskera, Mr. Curtis Garner, and Mr. Micky Wheeler for expert technical assistance and Mrs. Belinda Lambert for typing the manuscript.

This work was supported by National Heart and Lung Institute grants NL15522, HL15884, NHLI contract 722947, the Moss Heart Fund, the National Institutes of Health Ischemic Heart Center, and grants from the American Heart Association, Inc. (Dallas County Chapter).

\section{REFERENCES}

1. Willerson, J. T., W. J. Powell, Jr., T. E. Guiney, J. J. Stark, C. A. Sanders, and A. Leaf. 1972. Improvement in myocardial function and coronary blood flow in ischemic myocardium after mannitol. J. Clin. Invest. 51 : 2989-2998.

2. Rudolph, A. M., and M. A. Heymann. 1967. The circulation of the fetus in utero. Methods for studying distribution of blood flow, cardiac output and organ blood flow. Circ. Res. 21 : 163-184.

3. Kumar, R., W. B. Hood, Jr., J. Joison, J. C. Norman, and W. H. Abelmann. 1970. Experimental myocardial infarction. II. Acute depression and subsequent recovery of left ventricular function: serial measurements in intact conscious dogs. J. Clin. Invest. 49: 55-62.

4. Chimoskey, J. E., R. Szentivanyi, R. Zakheim, and A. C. Barger. 1967. Temporary coronary occlusion in conscious dogs: collateral flow and electrocardiogram. Am. J. Physiol. 212 : 1025-1032.

5. Maroko, P. R., J. K. Kjekshus, B. E. Sobel, T. Watanabe, J. W. Covell, J. W. Ross, Jr., and E. Braunwald. 1971. Factors influencing infarct size following experimental coronary artery occlusions. Circulation. 43: 6782.

6. Karlsson, J., G. H. Templeton, and J. T. Willerson. 1973. Relationship between epicardial ST-segment changes and myocardial metabolism during acute coronary insufficiency. Circ. Res. 32: 725-730.

7. Cohen, M. V., and E. S. Kirk. 1974. Reduction of epicardial ST-segment elevation following increased myocardial ischemia: experimental and theoretical demonstration. Clin. Res. 22: 269a.

8. Krug, A., W. du Mesnil M. de Rochemont, and G. Korb. 1966. Blood supply of the myocardium after temporary coronary occlusion. Circ. Res. 19: 57-62.

9. Flores, J., D. R. DiBona, C. H. Beck, and A. Leaf. 1972. The role of cell swelling in ischemic renal damage and the protective effect of hypertonic solute. $J$. Clin. Invest. 51: 118-126. 
10. Cantu, R. C., and A. Ames, III. 1969. Experimental prevention of cerebral vasculature obstruction produced by ischemia. J. Neurosurg. 30: 50-54.

11. Velasquez, M. T., A. V. Notargiacomo, and J. N. Cohn 1973. Comparative effects of saline and mannitol on renal cortical blood flow and volume in the dog. $\mathrm{Am}$. J. Physiol. 224 : 322-327.

12. Hauge, A., and G. B $\varnothing$. 1971. Blood hyperosmolality and pulmonary vascular resistance in the cat. Circ. Res. 28: 371-376.

13. Gazitùa, S., J. B. Scott, B. Swindall, and F. J. Haddy. 1971. Resistance responses to local changes in plasma osmolality in three vascular beds. Am. J. Physiol. 220: 384-391.

14. Overbeck, H. W., and G. J. Grega. 1970. Response of the limb vascular bed in man to intrabrachial arterial infusions of hypertonic dextrose or hypertonic sodium chloride solution. Circ. Res. 26: 717-731.
15. Willerson, J. T., J. T. Watson, R. Wiskera, D. E. Fixler, G. H. Templeton, and W. L. Sugg. 1974. Increased resistance to reflow in canine myocardium after myocardial ischemia and its alleviation by hyperosmolar mannitol. Clin. Res. 22: 313A.

16. Koch-Weser, J. 1963. Influence of osmolarity of perfusate on contractility of mammalian myocardium. Am. J. Physiol. 204 : 957-962.

17. Willerson, J. T., M. L. Weisfeldt, C. A. Sanders, and W. J. Powell, Jr. 1974. Influence of hyperosmolar agents on hypoxic cat papillary muscle function. Cardiovasc. Res. 8: 8-17.

18. Willerson, J. T., J. S. Crie, R. C. Adcock, G. H. Templeton, and K. Wildenthal. 1974. Influence of calcium on the inotropic actions of hyperosmotic agents, norepinephrine, paired electrical stimulation, and treppe. $J$. Clin. Invest. 54: 957-964. 